\title{
Articles
}

\section{Aetiology of Traumatic Tympanic Membrane Perforation in Ratnapura}

Perera M.C., MuruthaghapitiyaM.G.P.K., Kalupahana K.M.S.N., Madalagama U.M.A.P., Ekanayake W.E.M.P.L., Perera M.P.A.H..

General Hospital, Ratnapura, Sri Lanka.

\section{Introduction}

Tympanic membrane perforation is a condition as old as the human species. It is a common presentation in an E.N.T. unit and a frequent cause of morbidity.

\section{Objectives}

The aim of the study is to profile the etiological factors of Traumatic Tympanic Membrane perforation occurring in Ratnapura.

\section{Method}

A descriptive, prospective serial study was done at General Hospital Ratnapura. We analysed patients with tympanic membrane perforation during the study period of 6 months which started from $1^{\text {st }}$ April 2015.

\section{Results}

Fifty-two (52) cases of traumatic tympanic perforations were seen. There were $21(40.4 \%)$ females and 31(59.6\%) males. The mean age of younger patients $(<20 \mathrm{yrs})$ was 15years (STD 4$)$ and in adults ( $>=20 \mathrm{yrs}$ ) it was 35yrs (STD 9.8). The commonest aetiology was due to blows to the ear $(74.3 \%)$ and it commonly affects the left ear (80.8\%) of the victim. The commonest symptom was hearing impairment (31\%). Majority of the affected adults were females (51.4\%) and the source of blow was the husband (64.3\%).

\section{Conclusion and Recommendations}

Traumatic Tympanic membrane perforation is a common presentation. Educating school going children and taking steps to change social attitudes against violence especially against women may help to reduce incidence of Traumatic Tympanic membrane perforation.

\section{Introduction}

The Human tympanic membrane, is a thin, coneshaped membrane that separates the external ear from the middle ear. It is an important component in increasing sound energy transmission to the cochlear fluid relative to what would occur with a direct coupling of air to fluid. Tympanic membrane perforation is a condition as old as the human species ${ }^{1}$. It is a common presentation in an E.N.T. unit and a frequent cause of morbidity. Trauma is in the increase and is a burden to a developing country like Sri Lanka. Trauma patients consume more health care resources than heart and cancer patients combined and the incidence from trauma is on the increase $^{2,3}$. In this view it is important to identify, the etiological factors of traumatic tympanic membrane perforation so that authorities can take preventive action in curbing such incidents.

\section{Material and Methods.}

\section{Objectives}

The aim of the study is to profile the aetiological factors of Traumatic Tympanic Membrane perforation (TMP) occurring in patients attending the E NT Unit at General Hospital, Ratnapura.

\section{Method}

This descriptive, prospective serial study was done at General Hospital Ratnapura. The study sample included patients getting admitted to the E.N.T. ward and visiting the clinic with a tympanic membrane perforation during the study period of 6 months which started from $1^{\text {st }}$ April 2015. Only patients giving written consent were included in the study. The data was collected by medical officers using a questionnaire. Ethical clearance for the study was obtained from the 
National Institute of Health Sciences, Kalutara, Sri Lanka.

\section{Results}

The ENT unit had 2580 casualty admissions during this period inclusive of 52 cases of traumatic tympanic membrane perforations (TMP). These casualties consisted of 1 preschool child (6 months to 4yrs), 16 school aged and 35 adults (>20years) (table 1$)$.

\begin{tabular}{|lr|}
\hline $\begin{array}{c}\text { Table 1: Age distribution of patients } \\
\text { with traumatic TM perforation } \\
\text { Age (years) }\end{array}$ & $\begin{array}{l}\text { Frequency (\%) } \\
\text { <4yrs }\end{array}$ \\
$4-20 \mathrm{yrs}$ & $16(30.9 \%)$ \\
$>20 \mathrm{yrs}$ & $35(67.3 \%)$ \\
\hline Total & $52(100 \%)$ \\
\hline
\end{tabular}

Table 2: Age and Sex distribution of patients with traumatic TM perforation

\begin{tabular}{lll} 
& \multicolumn{2}{c}{ Age } \\
Male & $\frac{\leq 20 \mathrm{yrs}}{14(82.4 \%)}$ & $\begin{array}{c}>=20 \mathrm{yrs} \\
17(48.6 \%)\end{array}$ \\
Female & $3(17.6)$ & $18(51.4 \%)$ \\
\hline Total1 & $7(100 \%)$ & $35(100 \%)$ \\
\hline
\end{tabular}

Table 3: Aetiological profile of TM perforations

Aetiology $\quad$ Frequency(\%)

Assault (Blow) 39(75\%)

Self-trauma $\quad 6(11.5 \%)$

Accidental Trauma $7(13.5 \%)$

Total 52(100\%)

Table 4: Presenting complaints of the patients

\begin{tabular}{|c|c|}
\hline Presenting Complaint & Frequency $(\%)$ \\
\hline Bleeding & 7 (6.2\%) \\
\hline Fullness & $25(22.1 \%)$ \\
\hline Hearing impairment & $35 \quad(31 \%)$ \\
\hline Pain & $21(18.6 \%)$ \\
\hline Tinnitus & $22(19.5 \%)$ \\
\hline Vertigo & $2(1.8 \%)$ \\
\hline Discharge from ear & $1(0.9 \%)$ \\
\hline
\end{tabular}

There were 21(40.4\%) females and 31(59.6\%) males (table 2). The main cause of TMP was assault by a blow to the ear 39(75\%) (table $3)$. The presenting symptoms were hearing impairment 35(31\%), tinnitus 22(19.5\%) and feeling of fullness in the ear 25(22.1\%) (table $4)$. In $42(80.8 \%)$ of the cases the left ear was affected and in the rest $10(19.2 \%)$ the right ear was involved. None had bilateral TMP.

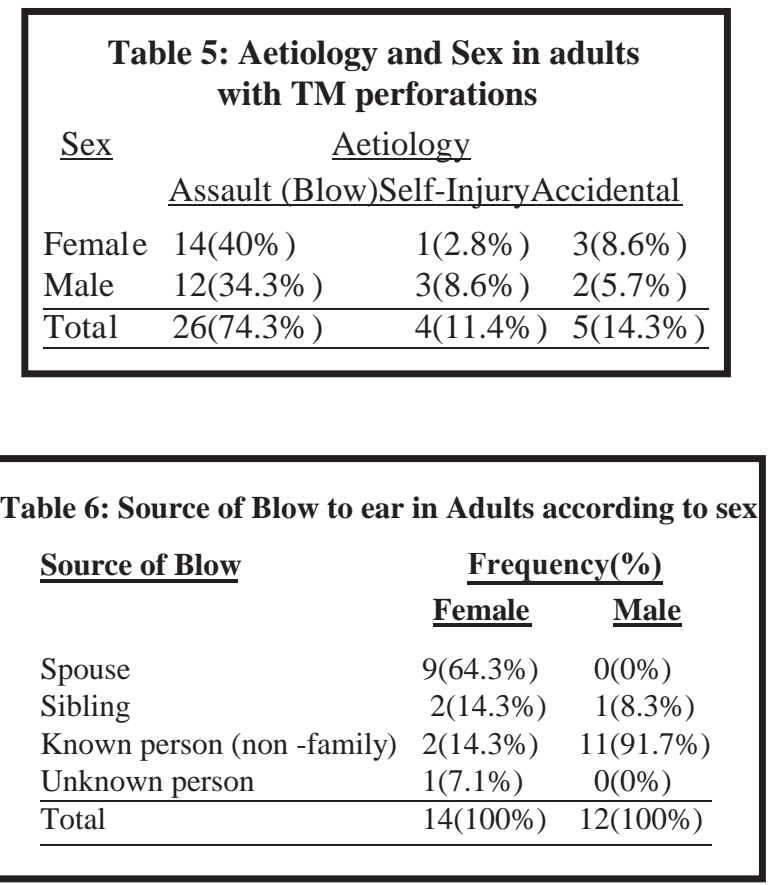

In adults, more females 25(53\%) were exposed to assaults by a blow than males 12(46.2\%). Majority of females $11(78.6 \%)$ were assaulted by family members and out of it $9(64.3 \%)$ has been by their husbands at home and four (44\%) of them were under the influence of alcohol. Only $2(14.3 \%)$ of the females were going to take legal action regarding the incident.

\section{Discussion}

Rupture of the tympanic membrane may be caused by changes in air pressure, by fluids or by solid objects ${ }^{4}$. The change in pressure is the commonest cause of tympanic membrane perforation in this study and most of this was due to trauma to the ear due to blows by hand (75\%). The less common pressure induced causes were accidental trauma (13.5\%) due to tennis balls hitting the ear and one case due to sound of thunder. Self-injury (11.5\%) although less common, was almost all due to the fact of using cotton buds to clear ear wax. 
The mean age of younger patients $(<20 \mathrm{yrs})$ was 15years (STD 4 ) and in adults ( $>=20 \mathrm{yrs}$ ) it was 35years (STD 9.8). In small and school going age (<20yrs) the majority (82.4\%) of TMP was in males. This could be due to their aggressive and active nature at this age. In adults ( $>=20 \mathrm{yrs}$ ) both males (48.6\%) and females (51.4\%) were equally affected. The aetiology of this was mainly blows to the ear $(74.3 \%)$. In females the assailant in majority of these cases were husbands (64.3\%). Almost half (44\%) of these incidents were related to consumption of alcohol. Only 2(14.3\%) of the affected females were planning to go for legal action as the majority were scared of the consequences of the action with regarad to their children. The authors view is that this incidence is only the tip of the iceberg, as many of the females after TMP following domestic violence tend to get treatment in the private sector, so that their numbers in state sector statistics are minimal.

The main presenting symptoms were hearing impairment (31\%), Fullness of the ear (22.1\%), Tinnitus (19.5\%) and pain (18.6\%). The involved ear was mainly the left $(80.8 \%)$. This could be due to most assailants being right handed with the victims facing them so that their left ear becomes more vulnerable.

TMP usually occurs in healthy members in the community and the general prognosis is excellent $^{5}$. The main factors which prevent TMP healing are large tissue loss and local infection. In many cases no active intervention is needed. Masterly inactivity and educating the patient to keep the ear dry by preventing water from entering the ear canal will help in getting a good outcome. If the perforation fails to close spontaneously in 3-6 months surgical closure is indicated ${ }^{5}$.

\section{Conclusions}

Traumatic Tympanic membrane perforation is a common presentation at the ENT unit Ratnapura Hospital. It affects mainly the school age males and adults of both sexes. The commonest aetiology is due to blows to the ear and it commonly affects the left ear of the victim. The commonest symptom is hearing impairment. The incidence of tympanic membrane perforation in adult females is higher, than in males and is due to violence by the husband in the majority and occurs at home.

\section{Key Messages}

Educating school going children and taking steps to change social attitude against violence especially against women and taking punitive action against the assailant may help to reduce incidence of Traumatic Tympanic membrane perforation.

TMP generally has a good prognosis. Masterly inactivity and educating the patient to keep the ear dry by preventing water from entering the ear canal will help in getting a good outcome. The patient needs referral if the perforation fails to close spontaneously in 3-6 months.

\section{References}

1. Benitez, J.T., Otopathology of Egyptian mummy Pum II: final report. J Laryngol Otol. Jun 1988;102(6):485-90.

2. Shires, G.T., Thal, E.R., Jones, R.C. et al.: Trauma. In Principles of surgery 6th edition. Edited by: Schwartz SI. New York: McGrawHill; 1994:175-224.

3. Miller, T.R., Waehrer, G.M., Costs of occupational injuries to teenagers, United States. Inj Prev 1998, 4:211-217.

4. Abbas, P. J., Miller, C.A., Physiology of the Auditory System: Cumming's Otolaryngology Head \& Neck Surgery, Ear and Cranial Base, 3rd Edn, Mosby-Year Books, Missouri; 1998. 2832-2833

5. Toner, J.G., Kerr, A.G., Ear Trauma. in ScottBrown's Otolaryngology, Otology, 6th edition. J. Butterworths Meinemann, London; 1997. 3/7/1-3/7/13 